\title{
ANALISA PENCATATAN PEMOTONGAN IURAN DANA PENSIUN PT. POS INDONESIA CABANG MANADO
}

\author{
Cynthia Imelda Mose ${ }^{1}$ \\ Inggriani Elim ${ }^{2}$ \\ ${ }^{1,2}$ Fakultas Ekonomi dan Bisnis Jurusan Akuntansi \\ Universitas Sam Ratulangi \\ email : \\ 11cynthia mose@yahoo.co.id \\ 2inggriani_elim@yahoo.com
}

\begin{abstract}
Everyone wants a prosperous life in old age. In the 1970s, people race to sign civil servants because only civil servants who have the assurance of a pension fund. However, in the 1990s after the issuance of Law No. 11 of 1992 on retirement funds, pension funds had not confined to civil servants but also the private sector employees. The purpose of this study was to determine the recording of deducting pension contributions PT. Pos Indonesia Cabang Manado. The analytical method used was descriptive method starts with collecting relevant data with research, analyzes how the recording of deduction contributions to pension funds, and draw conclusions. The results showed that the recording of pension contributions deduction made in accordance with accounting theory and the company only help in collecting and depositing pension contributions to the pension fund account.The company should mantain the recording of pension contribution deduction so the company's financial condition could be controlled, especially about pension contribution deduction.
\end{abstract}

Keywords: recording, pension fund 


\section{PENDAHULUAN}

\section{Latar Belakang}

Setiap manusia mendambakan kehidupan yang sejahtera di masa tuanya. Menurut Kasmir dalam bukunya yang berjudul Bank dan Lembaga Keuangan Lainnya mengatakan bahwa di era tahun 1970-an, masyarakat Indonesia berlomba untuk masuk menjadi pegawai negeri dengan tujuan untuk memperoleh pensiun di masa tuanya. Karena pada saat itu hanya pegawai negeri yang memiliki kepastian akan dana pensiun. Namun pada tahun 1992, pemerintah mengeluarkan peraturan mengenai dana pensiun, yaitu UU Nomor 11 Tahun 1992. Sebagaimana yang diamanatkan dalam Undang-Undang Nomor 11 Tahun 1992 tentang Dana Pensiun, dana pensiun tidak hanya milik pegawai negeri saja, melainkan telah terbuka untuk semua pekerja, baik pekerja swasta maupun perorangan. Menurut undang-undang tersebut, dana pensiun dikelompokkan menjadi dua jenis yaitu dana pensiun pemberi kerja (DPPK), dana pensiun lembaga keuangan (DPLK).

Dana pensiun diselenggarakan dalam upaya memberikan kesejahteraan pada karyawan. Oleh karenanya baik instansi pemerintah maupun swasta mengadakan program pensiun bagi para pegawainya, dan diharapkan dengan adanya program pensiun akan memberikan motivasi yang tinggi bagi karyawan sehingga akan memberikan keuntungan bagi perusahaan dan untuk meningkatkan produktivitas usahanya tercapai, sehingga akan menguntungkan baik bagi pihak perusahaan maupun karyawan itu sendiri.

Ketika karyawan sudah pensiun, mereka akan menerima haknya sebagai peserta pensiun dalam bentuk pembayaran secara berkala selama masa hidupnya dan apabila peserta program pensiun tersebut meninggal, maka sang ahli waris berhak menerima kelanjutan pembayaran pensiun tersebut. Hal ini disebut dengan manfaat telah menjadi hak (vested benefits).

PT. Pos Indonesia merupakan salah satu perusahaan milik negara yang menjalankan prgram pensiun bagi karyawannya sebagai imbalan atas jasa yang telah diberikan selama masa bakti karyawan. Iuran pensiun dihimpun dari karyawan selama masa kerja yang langsung dipotong dari gaji karyawan setiap bulannya.Ketika perusahaan menghimpun iuran pensiun dari pemotongan gaji karyawan, maka perusahaan akan melakukan pencatatan pemotongan iuran pensiun terhadap gaji karyawan.

\section{Tujuan Penelitian}

Tujuan penelitian ini adalah untuk mengetahui bagaimana pencatatan pemotongan iuran dana pensiun yang dilakukan oleh PT. Pos Indonesia Cabang Manado.

\section{TINJAUAN PUSTAKA}

\section{Definisi Akuntansi}

Menurut Taswan (2015:5) secara umum akuntansi bisa didefinisikan sebagai seni, ilmu, sistem informasi yang di dalamnya menyangkut pencatatan, pengklasifikasian, dan pengikhtisaran dengan cara sepatutnya dan dalam satuan uang atas transaksi dan kejadian yang setidak-tidaknya sebagian mempunyai sifat keuangan serta adanya penginterpretasian hasil pencatatan dan disajikan dalam laporan keuangan.

Sedangkan menurut Charles T. Horngren, dan Walter T.Harrison menyatakan bahwa: Akuntansi adalah sistem informasi yang mengukur aktivitas bisnis, memproses data menjadi laporan, dan mengkomunikasikan hasilnya kepada para pengambil keputusan. 


\section{Program Manfaat Purnakarya (Dana Pensiun)}

Menurut PSAK Nomor 18, Program Manfaat Purakarya adalah perjanjian untuk setiap entitas yang menyediakan manfaat purnakarya untuk karyawan pada saat atau setelah berhenti bekerja (baik dalam bentuk iuran bulanan atau lumpsum) ketika manfaat semacam itu, atau iuran selanjutnya untuk karyawan, dapat ditentukan atau diestimasi sebelum purnakarya berdasarkan ketentuan-ketentuan yang terdapat dalam dokumen atau praktik-praktik entitas.

Dalam UU Nomor 11 Tahun 1992 yang mengatur tentang Dana Pensiun dikatakan bahwa:

"Dana Pensiun adalah badan hukum yang mengelola dan menjalankan program yang menjanjikan manfaat pesiun."

Menurut Fahmi (2014: 176) pengertian secara umum dana pensiun adalah sebuah keputusan yang dibuat untuk menyiapkan sejumlah dana atau membangun perencanaan keuangan agar dana tersebut dapat dipakai ketika pensiun dalam membiayai masa-masa pensiun.

\section{Manfaat Telah Menjadi Hak (Vested Benefit)}

Berdasarkan Undang-undang Nomor 11 Tahun 1992, Manfaat Pensiun adalah pembayaran berkala yang dibayarkan kepada peserta pada saat dan dengan cara yang ditetapkan dalam peraturan Dana Pensiun. Menurut PSAK No.18, manfaat telah menjadi hak adalah manfaat purnakarya untuk hak manfaat purnakarya dalam kondisi sesuai dengan program manfaat purnakarya yang tidak bergantung pada kelangsungan ikatan kerja.

Taswan (2015:5) manfaat pensiun terdiri dari:

1. Manfaat pensiun normal

2. Manfaat pensiun dipercepat

3. Manfaat pensiun cacat

4. Manfaat pensiun ditunda

5. Manfaat pensiun janda/duda/anak

\section{Asas-Asas Dana Pensiun}

Menurut Undang-Undang Nomor 11 Tahun 1992, penyelenggaraan dana pensiun didasarkan pada 5 (lima) asas pokok. Asas-asas tersebut adalah sebagai berikut:

1. Asas keterpisahan kekayaan dana pensiun dari kekayaan dana pendirinya.

2. Asas penyelenggaraan dalam system pendanaan.

3. Asas pembinaan dan pengawasan.

4. Asas penundanaan manfaat.

5. Asas kebebasan untuk membentuk atau tidak membentuk dana pensiun.

\section{Sistem Pembayaran Pensiun}

Pada saat akan menerima pensiun, perusahaan biasanya menawarkan dua macam sistem pembayaran kepada karyawan. Ada dua jenis pembayaran pensiun yang biasa dilakukan, yaitu:

1. Program Pensiun Manfaat Pasti (PPMP)

Berdasarkan PSAK No.18, program iuran pasti adalah program manfaat purnakarya dimana jumlah yang dibayarkan sebagai manfaat purnakarya ditetapkan berdasarkan iuran ke suatu dana bersama pendapatan investasi selanjutnya.

2. Program Pensiun Iuran Pasti (PPIP)

Menurut Bapepam, manfaat pasti atau program pensiun manfaat pasti (PPMI) adalah manfaat (uang atau benefit saat pensiun) telah ditentukan berdasarkan rumus tertentu yang telah ditetapkan di awal. Umumnya perusahaan akan mempertimbangkan masa atau lama bekerja dan besarnya penghasilan. 


\section{Pendanaan}

Menurut PSAK No.18, pendanaan adalah transfer aset kepada entitas (dana purnakarya) yang terpisah dari entitas pemberi kerja guna memenuhi kewajiban masa depan untuk pembayaran manfaat purnakarya. Pendanaan oleh pemberi kerja dicatat sebagai Iuran Pemberi Kerja (IPK) yang diberikan perusahaan sebagai subsidi untuk program dana pensiun untuk memenuhi kewajiban pembayaran manfaat pensiun di masa depan juga sebagai bentuk penghargaan atas jasa karyawan selama masa kerjanya. Persentase dari Iuran Pemberi Kerja (IPK) biasanya tergantung pada kebijakan perusahaan pemberi kerja.

\section{Peserta}

Berdasarkan PSAK No.18, peserta program manfaat purnakarya adalah anggota dari program manfaat purnakarya yang berhak menjadi penerima manfaat purnakarya. Berdasarkan Undang-Undang Nomor 11 Tahun 1992, usia peserta pensiun dibedakan ke dalam 4 kategori, yaitu:

1. Pensiun normal (normal retirement)

2. Pensiun dipercepat (early retirement)

3. Pensiun ditunda (deferred retirement)

4. Pensiun cacat

\section{Jenis Kelembagaan Dana Pensiun}

UU No 11 tahun 1992 pasal 2 jenis kelembagaan dana pensiun dibatasi dalam 2 jenis yaitu dana pensiun pemberi kerja (DPPK) dan dana pensiun lembaga keuangan (DPLK). DPPK, lembaga ini dibentuk oleh orang atau badan yang memperkerjakan karyawan, selaku pendiri dan penyelenggaraan program pensiun manfaat pasti atau program pensiun iuran pasti bagi kepentingan sebagian atau seluruh karyawan sebagai peserta. DPLK merupakan dana pensiun yang dibentuk oleh bank dengan status bank umum atau perusahaan asuransi jiwa yang menyelenggarakan program pensiun iuran pasti bagi perorangan.

\section{Pencatatan Pemotongan Iuran Pensiun}

Pencatatan iuran pensiun menurut Hery (2014:308) jumlah gaji bruto (kotor) adalah besarnya gaji pokok ditambah dengan tunjangan-tunjangan, sebelum dikurangi dengan potongan-potongan. Jumlah gaji bruto setelah dikurangi dengan potongan-potongan, dinamakan gaji bersih. Potongan-potongan yang mengurangi jumlah gaji yang diterima oleh karyawan biasanya terdiri atas potongan untuk pajak penghasilan dan jaminan sosial tenaga kerja (jamsostek).

Tabel 2.1 Ayat Jurnal Potongan Iuran Pensiun

\begin{tabular}{|c|l|c|c|}
\hline Tanggal & Nama Perkiraan & Debet & Kredit \\
\hline 28 & Beban Gaji & Xxx & \\
Januari & Utang pajak penghasilan karyawan & & xxx \\
& Utang pajak jaminan sosial & & Xxx \\
& Utang iuran pensiun & & xxx \\
& Piutang karyawan & & xxx \\
& Kas & & xxx \\
& & & \\
\hline
\end{tabular}

Sumber: Hery (2014:313)

Akun beban gaji didebet dalam jurnal sebesar jumlah gaji bruto (gaji pokok ditambah dengan seluruh tunjangan yang ada dan sebelum dikurangi dengan potongan-potongan). Dalam jurnal diatas, asumsi bahwa jumlah gaji bersih yang dibayarkan (kas) adalah besarnya gaji bruto setelah dikurangi dengan potonganpotongan untuk pajak penghasilan, jamsostek, iuran pensiun, dan angsuran pinjaman.

Pada saat iuran pensiun yang dipotong dan dipungut sebagian dari gaji karyawan disetorkan ke lembaga dana pensiun, ayat jurnal yang akan dibuat adalah: 
Utang iuran pensiun
Kas

Pada saat utang atas sebagian iuran pensiun yang dikontribusikan oleh pemberi kerja disetorkan ke lembaga dana pensiun, ayat jurnal yang dibuat adalah:

Utang iuran pemberi kerja
Kas

\section{Penelitian Terdahulu}

1. Bukit (2012) dengan judul Analisis Penerapan Pernyataan Standar Akuntansi No 18 Mengenai Dana Pensiun pada PT PERTAMINA. Tujuannya untuk mengetahui prosedur dan perlakuan dana pensiun yang diterapakan pada dana pensiun PT. Pertamina. Metode yang digunakan yaitu deskriptif kualitatif. Hasil penelitiannya proses akuntansi yang diterapkan oleh Dana Pensiun Pertamina (DPP) secara keseluruhan telah sesuai dengan PSAK yang berlaku dan beberapa peraturan yang berhubungan dengan Akuntansi Dana Pensiun.

2. Nussy (2014) dengan judul Analisis Penerapan Standar Akuntansi Keuangan No 18 Mengenai Dana Pensiun pada PT. Taspen cabang Manado. Tujuannya untuk menganalisis kesesuaian penerapan dana pensiun pada PT. Taspen cabang Manado dengan PSAK Nomor 18. Metode yang digunakan yaitu metode deskriptif kualitatif. Hasil penelitiannya yaitu informasi yang diungkapkan dalam laporan keuangan dana pensiun taspen 2012-2013, penyajiannya telah sesuai dengan pernyataan standar akuntansi keuangan nomor 18.

\section{METODE PENELITIAN}

\section{Jenis Penelitian}

Jenis penelitian yang digunakan adalah penelitian deskriptif. Menurut Sugiyono (2012:13) penelitian deskriptif yaitu penelitian yang dilakukan untuk mengetahui variabel mandiri, baik satu variabel atau lebih (independen) tanpa membuat perbandingan, atau menghubungkan dengan variabel lain. Dalam penelitian ini, penulis ingin menganalisa bagaimana pencatatan yang dilakukan dalam pemotongan iuran pada PT. Pos Indonesia Cabang Manado.

\section{Tempat dan Waktu Penelitian}

Penelitian dilaksanakan pada PT. Pos Indonesia cabang Manado yang terletak di Jl. Sam Ratulangi No.21-23, Manado. Waktu penelitian dimulai Maret-April 2016.

\section{Prosedur Penelitian}

Prosedur penelitian yang dilakukan adalah sebagai berikut:

1. Mengajukan permohonan penelitian.

2. Tindak lanjut dari pihak perusahaan, dalam bentuk surat yang menyatakan pihak perusahaan telah memberi izin untuk melakukan penelitian di PT. Pos Indonesia Cabang Manado.

3. Mengumpulkan data.

4. Menganalisis data dan mengolah data yang diperoleh dari perusahaan.

5. Menarik kesimpulan dari hasil analisis data dan memberikan saran. 


\section{Jenis Data}

(Sugiyono, dikutip dalam Nussy 2010:13) menyatakan bahwa dalam penelitian ada dua jenis data yang digunakan yaitu data kuantitatif dan data kualitatif sebagai berikut:

1. Data kuantitatif dapat diartikan sebagai metode penelitian yang berlandaskan pada filsafat positivisme, digunakan untuk meneliti pada populasi atau sampel tertentu, teknik pengambilan sampel pada umumnya dilakukan secara random, pengumpulan data menggunakan instrumen penelitian, analisis data bersifat kuantitatif/statistik dengan tujuan untuk menguji hipotesis yang telah ditetapkan.

2. Data kualitatif dapat diartikan metode penelitian yang berlandaskan pada filsafat positivisme, digunakan untuk meneliti pada kondisi objek yang alamiah, dimana peneliti adalah sebagai instrumen kunci, pengambil sampel sumber data dilakukan secara purposive dan snowball, teknik pengumpulan dengan trianggulasi, analisis data bersifat induktif/kualitatif dan hasil penelitian kualitatif lebih menekankan makna daripada generalisasi. Jenis data yang digunakan dalam penelitian ini adalah data kualitatif berupa sampel sumber data sebagai alat menganalisis keterangan apa yang ingin diketahui.

Jenis data yang digunakan dalam penelitian ini bersifat kuantitatif, dimana data tersebut adalah slip gaji dan jurnal pencatatan akuntansi dari PT. Pos Indonesia.

\section{Sumber Data}

Sumber data adalah tempat dimana data diperoleh yang dapat memberikan informasi bagi penulis. Sumber data dibagi menjadi dua, yaitu:

1. Data Primer adalah data yang diperoleh dan dikumpulkan langsung dari responden.

2. Data Sekunder adalah data yang sudah jadi. Data tersebut bersumber dari catatan yang ada pada perusahaan dan dari sumber lainnya yaitu dengan mengadakan studi kepustakaan dengan mempelajari buku-buku yang ada hubungannya dengan obyek penelitian. (Sunyoto 2013:21)

Sumber data yang digunakan dalam penelitian ini adalah data primer dan data sekunder. Data primer diperoleh dari hasil wawancara mengenai hal yang bersangkutan dengan penelitian ini, sedangkan data sekunder adalah data dari dokumen perusahaan, berupa sejarah perusahaan, serta dokumen yang berhubungan dengan tujuan penelitian.

\section{Teknik Pengumpulan Data}

Teknik pengumpulan data yang digunakan dalam penelitian ini adalah:

1. Teknik Wawancara, dilakukan dengan wawancara secara langsung terhadap pihak yang terkait tentang program manfaat purnakarya.

2. Teknik Dokumentasi, dilakukan dengan mengumpulkan dokumen yang dapat memberikan informasi mengenai penelitian.

3. Teknik Perpustakaan, yaitu dengan mengumpulkan informasi dari buku dan jurnal ilmiah lainnya.

\section{Metode Analisis}

Metode analisis yang digunakan adalah metode deskriptif kualitatif yang dimulai dari mengumpulkan data, disusun, dianalisa sehingga dapat memberikan gambaran bagaimana perlakuan pencatatan pemotongan iuran pensiun dari PT. Pos Indonesia. 


\section{HASIL PENELITIAN DAN PEMBAHASAN}

\section{Hasil Penelitian}

Sejalan dengan meningkatnya angkatan kerja, timbul suatu kesadaran bahwa hidup mereka sangat bergantung pada perusahaan dimana mereka bekerja. Persoalan berhenti bekerja atau persoalan hari tua dapat berpengaruh pada konsentrasi kerja karyawan yang akhirnya berpengaruh pada tingkat produktivitas kerja karyawan Menyikapi kondisi tersebut, salah satu solusi yang dilakukan Perusahaan yang berkaitan dengan jaminan hari tua karyawan adalah didirikannya Dana Pensiun Pos Indonesia (Dapenpos) dengan Keputusan Direksi PT Pos Indonesia (Persero) tentang Peraturan Dana Pensiun yang telah mengalami perubahan dan penyempurnaan dan terakhir ditetapkan berdasarkan Keputusan Direksi PT Pos Indonesia (Persero) Nomor : KD.61/Dirut/0712 tanggal 25 Juli 2012 tentang Peraturan Dana Pensiun dari Dana Pensiun Pos Indonesia yang disahkan dengan Keputusan Menteri Keuangan Republik Indonesia Nomor : KEP-770/KM.10/2012 tanggal 28 Desember 2012.

Sebagai konsekuensi atas didirikannya Dapenpos, maka penjabaran atas maksud dan tujuan harus dilakukan secara terencana dan sistematis. Dengan demikian, penyusunan Rencana Jangka Panjang (RJP) Dapenpos merupakan suatu keharusan, yang akan dipergunakan sebagai Panduan (Road-Map) arah pengembangan Dapenpos 5 (lima) tahun mendatang. Penyusunan rencana secara formal ini akan memudahkan Dapenpos dalam menyusun Rencana Perubahan atau penyesuaian apabila terjadi perubahan lingkungan usaha maupun kondisi internal Pendiri maupun Dapenpos yang memberikan dampak terhadap pengelolaan Dapenpos. Rencana Jangka Panjang (RJP) Dapenpos disusun secara kualitatif maupun kuantitatif berbasis asumsi yang mendasarinya, yang berfungsi sebgai pedoman dalam menerapkan tahapan sasaran yang akan dicapai secara berkesinambungan, terkait dengan dukungan pendanaan jangka panjang menyangkut kesejahteraan Peserta, dengan tetap memperhatikan pengelolaan risiko dan prinsip kehati-hatian, serta going concern Dapenpos.

\section{Tata Kelola Dana Pensiun}

a. Pemotongan Iuran Pensiun

Iuran pensiun pegawai PT. Pos Indonesia akan langsung dipotong dari gaji bruto pegawai setiap bulannya sejak dia diangkat menjadi pegawai di PT. Pos Indonesia.

b. Penyetoran Iuran Pensiun

Iuran yang sudah dipotong dari gaji pegawai, kemudian akan disetorkan oleh bagian Gaji ke rekening Dapenpos melalui Giro Pos selambat-lambatnya tanggal 5 setiap bulan berjalan.Apabila setelah dilakukan evaluasi dan rekonsiliasi atas iuran pensiun terdapat kekurangan pembayaran, maka kekurangan tersebut dibebankan ke anggaran perusahaan.

c. Pembayaran Manfaat Pensiun

Pembayaran manfaat pensiun PT. Pos Indonesia dibayarkan secara tunai di setiap Kantor Pos pada tanggal 1 s/d 9 setiap bulannya. Dapenpos Pusat akan mengirimkan data para penerima manfaat pensiun dalam bentuk hard copy ke bagian SDM. Selanjutnya jumlah manfaat pensiun akan dibayarkan sesuai dengan yang tertera di data tersebut.

Apabila ada anggota purnabakti yang belum mengambil manfaat pensiun pada tanggal yang sudah ditentukan, maka jumlah manfaat pesiun yang belum dibayarkan tersebut akan dikembalikan ke rekening Dapenpos. Manfaat pensiun yang belum diambil oleh anggota purnabakti akan dibuat laporan pertanggungjawaban terpisah dengan yang sudah terbayar.Setiap dua tahun sekali, besar manfaat pensiun dari Dapenpos yang diterima oleh pensiunan/janda/duda dan anak pada bulan Januari tahun genap meningkat sebesar 6\% (enam per seratus) dari manfaat pensiun pokok bulan Desember tahun sebelumnya 


\section{Pencatatan}

Berdasarkan hasil wawancara yang dilakukan peneliti dengan karyawan bagian keuangan khususnya yang menangani tentang dana pensiun, contoh pencatatan jurnal pada saat pemotongan iuran pensiun adalah sebagai berikut

$\begin{array}{ccc}\text { Beban Gaji } & \text { xxx } & \\ \text { Beban IPK } & \text { xxx } & \\ \text { Hutang Iuran Pensiun } & & \text { xxx } \\ \text { Hutang IPK } & \text { xxx } \\ \text { Sumbangsih } & \text { xxx } \\ \text { Iuran Dana Kematian } & \text { xxx } \\ \text { Kas } & \text { xxx }\end{array}$

Pada jurnal diatas, dapat dilihat bahwa perusahaan mendebet beban gaji sebesar gaji bruto (belum dikurangi potongan-potongan) kemudian mengkredit hutang iuran pensiun, sumbangsih, iuran dana kematian, kewajiban pegawai lainnya, dan kas. Hasil antara jumlah gaji bruto dikurangi dengan potongan-potongan tersebut adalah jumlah gaji yang akan diterima oleh pegawai perusahaan. Untuk besarnya sumbangsih ditentukan sebesar Rp.3.500/org dan untuk iuran dana kematian ditentukan sebesar Rp.2000/org. Sedangkan untuk iuran pensiun, jumlah potongan adalah sebesar 5\% dari penghasilan dasar pensiun.

Pada saat perusahaan membebankan iuran pensiun terhadap gaji karyawan, maka akan muncul kewajiban bagi perusahaan untuk menyetorkan iuran pensiun karyawan ke pengelolan dana pensiun dimana seperti yang telah diatur bahwa beban iuran pemberi kerja (IPK) adalah sebesar 13,50\% dari penghasilan dasar pensiun atau sesuai dengan perhitungan aktuaria Dapenpos. Penyetoran dana pensiun pada PT. Pos Indonesia dilakukan melalui Giro Pos. Dan saat perusahaan melakukan penyetoran ke rekening dana pensiun, maka perusahaan akan mencatat dengan jurnal sebagai berikut

$\begin{array}{ll}\text { Hutang Iuran Pensiun } & \text { xxx } \\ \text { Hutang IPK } & \text { xxx }\end{array}$

Kas $\quad \mathrm{xxx}$

Untuk menyelesaikan kewajiban perusahaan, maka pada saat melakukan penyetoran, akun hutang iuran pensiun dan hutang iuran pemberi kerja akan dicatat di sebelah debet dan mengkredit akun kas.

\section{Pembahasan}

Berdasarkan hasil wawancara yang dilakukan penulis dengan pegawai PT. Pos Indonesia Cabang Manado bagian keuangan khususnya gaji, iuran pensiun terdiri dari iuran normal yang merupakan tanggungan karyawan perusahaan ditetapkan sebesar 5\% x Penghasilan Dasar Pensiun dan iuran normal yang menjadi tanggungan pemberi kerja ditetapkan sebesar 13,50\% x Penghasilan Dasar Pensiun.

Sebagai contoh, misalkan seorang karyawan memiliki gaji dasar sebesar Rp. 2.400.000,- dengan iuran peserta (IP) sebesar 5\% dan iuran pemberi kerja (IP) sebesar 13,50\%. Jurnal yang dicatat untuk pencatatan gaji pegawai jika tidak ada potongan adalah

$$
\begin{array}{r}
\text { Beban Gaji } \\
\text { Kas }
\end{array}
$$

Tetapi karena adanya potongan terhadap gaji dasar karyawan, maka perusahaan akan mencatat jurnal sebagai berikut:

$$
\begin{array}{cl}
\text { Beban Gaji } & \text { Rp 2.400.000,- } \\
\text { Beban IPK } & \text { Rp. 324.000,- } \\
\text { Hutang Iuran Pensiun } & \multicolumn{1}{c}{\text { Rp 120.000,- }}
\end{array}
$$




$\begin{array}{ll}\text { Hutang IPK } & \mathrm{Rp} 324.000,- \\ \text { Sumbangsih } & \mathrm{Rp} 3.500,- \\ \text { Iuran Dana Kematian } & \mathrm{Rp} 2.000,- \\ \text { Kas } & \mathrm{Rp} 2.274 .500,-\end{array}$

Karena iuran pensiun peserta langsung dipotong pada gaji karyawan, maka disebelah debet beban gaji akan dicatat Rp 2.400.000,- dan disebelah kredit kas akan dicatat sebesar Rp 2.274.500,- sedangkan sisanya Rp 125.500,- terdiri dari $\mathrm{Rp} 120.000$,- $(\mathrm{Rp} 2.400 .000$ x iuran pensiun 5\%), sumbangsih $\mathrm{Rp} 3.500$,- dan iuran dana kematian Rp 2.000,- akan dicatat di sebelah kredit sebagai potongan langsung gaji karyawan

Akun iuran pensiun dianggap tidak mempengaruhi kas karena merupakan kewajiban dari setiap karyawan untuk membayar iuran pensiun tersebut. Dalam hal ini perusahaan hanya membantu untuk menyetorkan iuran pensiun ke Dapenpos dari hasil potongan iuran pensiun karyawan.

Perusahaan juga menjalankan kewajiban sebagai pemberi kerja dengan membayar iuran pensiun selaku beban perusahaan yang akan dibayarkan oleh perusahaan sendiri. Besarnya iuran yang dibayarkan adalah 13,50\% sehingga perusahaan mencatat jurnal beban iuran pemberi kerja (IPK) disebelah debet sebesar Rp 324.000,- $\backslash$ dan mencatat sebelah kredit hutang IPK. Rp 324.000,- diperoleh dari hasil hitungan besarnya IPK 13,50\% x gaji karyawan sebesar Rp 2.400.000,-. Pada saat disetorkan ke rekening dana pensiun (Dapenpos), perusahaan akan menghapus kewajiban mereka terhadap iuran pensiun karena tanggung jawab dari perusahaan hanya menghimpun dan menyetorkan iuran dana pensiun ke rekening Dapenpos. Selanjutnya pihak Dapenposlah yang bertanggung jawab untuk mengelola iuran dana pensiun dan menyalurkan kepada para peserta dana pensiun pada saat peserta memasuki masa pensiunnya. Untuk itu, maka perusahaan akan mencatat jurnal sebagai berikut:

$$
\begin{array}{ll}
\text { Hutang Iuran Pensiun } & \text { Rp 120.000,- } \\
\text { Hutang IPK } & \text { Rp. 324.000,- } \\
\text { Kas } &
\end{array}
$$

Penyetoran iuran pensiun dari peserta pensiun maupun pemberi kerja dilakukan paling lambat tanggal 5 setiap bulan berjalan yang akan disetorkan ke rekening Dapenpos melalui giro pos dengan bukti setoran akan diserahkan ke bagian Gaji yang akan disimpan sebagai bukti bahwa iuran pensiun telah disetorkan.Dalam melakukan pencatatan pemotongan iuran pensiun, PT. Pos Indonesia Cabang Manado melakukan pencatatan jurnal berdasarkan teori pencatatan beban gaji dan potongan dalam akuntansi penggajian pada umumnya seperti pada tabel berikut.

Tabel 4.1 Perbandingan Pencatatan Pemotongan Iuran Pensiun menurut Teori dengan Perlakuan di Perusahaan

\begin{tabular}{|l|l|}
\hline \multicolumn{1}{|c|}{$\begin{array}{l}\text { Pencatatan Berdasakan Teori } \\
\text { (Hery,2014) }\end{array}$} & Perlakuan di Perusahaan \\
\hline $\begin{array}{l}\text { Akun beban gaji didebet dalam jurnal } \\
\text { sebesar jumlah gaji bruto (gaji pokok } \\
\text { ditambah dengan seluruh tunjangan yang } \\
\text { ada dan sebelum dikurangi dengan } \\
\text { potongan-potongan) }\end{array}$ & $\begin{array}{l}\text { Perusahaan mendebet beban gaji } \\
\text { sebesar gaji bruto yang belum dikurangi } \\
\text { dengan potongan-potongan serta mendebet } \\
\text { beban iuran pemberi kerja }\end{array}$ \\
\hline $\begin{array}{l}\text { Jumlah gaji bersih yang dibayarkan } \\
\text { (kas) adalah besarnya gaji bruto setelah } \\
\text { dikurangi dengan potongan-potongan untuk } \\
\text { pajak penghasilan, jamsostek, iuran, } \\
\text { pensiun, dan angsuran pinjaman. }\end{array}$ & $\begin{array}{l}\text { Perusahaan mengkredit kas setelah gaji } \\
\text { pensiun dan mengkredit iuran pensiun } \\
\text { sebagai pengurang beban gaji serta } \\
\text { mengkredit iuran pemberi kerja. }\end{array}$ \\
\hline
\end{tabular}

Sumber: Hasil olahan penulis 


\section{PENUTUP}

\section{Kesimpulan}

Berdasarkan hasil dari penelitian yang telah dilakukan penulis, maka dapat ditarik kesimpulan bahwa:

1. Perlakuan pencatatan pemotongan iuran pensiun pada PT. Pos Indonesia Cabang Manado sesuai dengan teori pencatatan potongan iuran pensiun pada umumnya.

2. Penyetoran iuran pensiun ke rekening dana pensiun dilakukan selambat-lambatnya tanggal 5 setiap bulan berjalan;

3. Besar manfaat pensiun dari Dapenpos yang diterima oleh peserta pensiunan/janda/duda dan anak pada bulan Januari tahun genap meningkat sebesar 6\% (enam per seratus) dari manfaat pensiun pokok bulan Desember tahun sebelumnya setiap dua tahun sekali;

4. Besarnya iuran pensiun peserta adalah $5 \%$ x penghasilan dasar pensiun, sedangkan iuran pemberi kerja adalah $13,50 \%$ x penghasilan dasar pensiun;

\section{Saran}

Dari hasil penelitian penulis di perusahaan, maka saran yang dapat diberikan oleh penulis adalah perusahaan sebaiknya tetap mempertahankan sistem pencatatan pemotongan iuran pensiun yang benar sesuai dengan teori pencatatan jurnal potongan iuran pensiun agar kondisi keuangan perusahaan bisa tetap terkontrol khususnya mengenai pemotongan iuran pensiun.

\section{DAFTAR PUSTAKA}

Bukit, Elvina. Octavia.2012.Analisis Penerapan PSAK No.18 Mengenai Akuntansi Dana Pensiun pada Dana Pensiun PT. Pertamina, Skripsi.Program Studi Akuntansi Fakultas Ekonomi dan Bisnis Universitas Hasanuddin Makassar.

Harahap, Sofyan.2013. Teori Akuntansi, Edisi Revisi, Cetakan Ketigabelas. Rajawali Pers. Jakarta.

Hendro, T., Rahardja, C.T.2014.Bank dan Institusi Keuangan Non Bank di Indonesia.Yogyakarta:UPP STIM YKPN

Hery.2014.Akuntansi Dasar 1 \& 2.Jakarta:Kompas Gramedia

Horngren, C.T., Walter, T.Harrison Jr., M.Suzanne Oliver.2012. Accounting $9^{\text {th }}$ Edition.Pearson Education Inc.

Ikatan Akuntan Indonesia (IAI), 2010, ED PSAK No.18 (revisi 2010)

Kasmir.2014.Bank dan Lembaga Keuangan Lainnya Edisi Revisi 2014.Jakarta:Rajawali Pers.

Nussy, F. P. Andika.2014.Analisis Penerapan PSAK No.18 Mengenai Akuntansi Dana Pensiun pada PT. Taspen Cabang Manado, Skripsi.Fakultas Ekonomi dan Bisnis Universitas Sam Ratulangi.

Pontoh, W.2013.Akuntansi Konsep Dan Aplikasi.Halaman Moeka.Jakarta.

Sugiyono, 2012. Metode Penelitian Pendidikan Pendekatan Kuantitatif, Kualitatif, dan R\&D. Alfabeta.Bandung.

Sunyoto, Danang.2013. Metodologi Penelitian Akuntansi. PT. Refika Aditama. Bandung

Taswan.2015.Akuntansi Perbankan, Edisi III.YogyakartaUPP STIM YKPN. 